\title{
Cognitive Profile of Patients with Schizophrenia in North Sumatera Indonesia
}

\author{
Mustafa M. Amin*, Elmeida Effendy, Bahagia Loebis \\ Department of Psychiatry, Faculty of Medicine, Universitas Sumatera Utara, Jl. dr. T. Mansur No.5 Medan, Indonesia
}

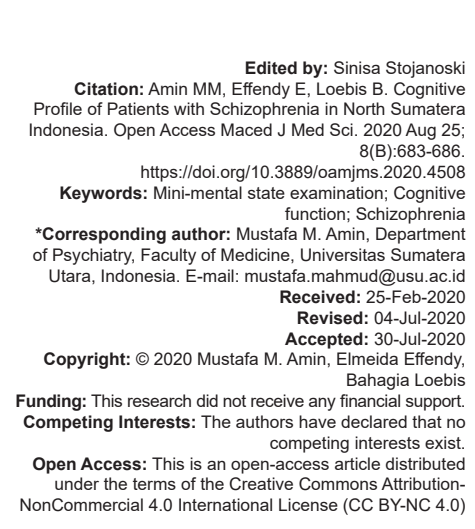

\section{Background}

Schizophrenia is a severe psychiatric disorder with a multifactorial and complex etiology. The prevalence of schizophrenia is around $1 \%$ worldwide. This disorder usually appears on younger patients, though it is likely to appear on to all ages. Women and men stand the same chance of contacting this disease, though men tend to have onset earlier than women. The initial age for patients suffering from schizophrenics was between 10 and 25 years for men, and 25 and 35 years for women. However, the current study has it that about $90 \%$ of patients receiving schizophrenia treatment are between the ages of 15 and 55 years of age [1].

Schizophrenia has a characteristic deficit in executive, memory, and general intellectual functions [2]. Some contrasting opinions about cognitive function in schizophrenia still exist. The first opinion suggests that cognitive deficits become progressively worse during the duration of the disease. As the symptom gradually develops, the patient's intellectual function weakens, and they become socially abusive. The second opinion suggests that once the cognitive deficits appear, they will be relatively stable [3].
The mini-mental state examination (MMSE) was originally designed to provide a brief and standardized assessment of mental status that can distinguish between functional and organic disorders in psychiatric patients. Over the years, there has been an increase in the test experience; however, its recent main function is to detect and track the progression of cognitive function associated with neurocognitive disorders [4]. The previous studies proved that MMSE itself was used in the measurement of patients with schizophrenia (PwS) in the United States of America, Singapore, and other countries due to it short administration time and available in validated many languages [5]. The analysis of cognitive function in PwS has been frequently carried out in various parts of the world, and thus, due to the varieties of tribes in the North Sumatera, a study should be done as a specific study of its own.

\section{Methods}

This study was a descriptive study which uses a cross-sectional approach [6] to determine the profile of cognitive function in PwS in North 
Sumatera Indonesia. The study subjects consisted of schizophrenic patients diagnosed according to the $10^{\text {th }}$ edition of the International Classification of Disease and Related Health Problems (ICD-10). The diagnosis was made by a psychiatrist (MMA), and his colleagues $(E E)$, and $(B L)$ before the fulfillment of inclusion and exclusion criteria.

The study made use of the following inclusion criteria: (1) Outpatient schizophrenic who met the diagnostic criteria for ICD-10, (2) patients between the ages of 15-55 years old, (3) cooperative and interview-able patients, (4) those capable of speaking the Indonesian language, (5) patients who must have at least graduated from primary school, and (6) those willing to participate in the study, confirmed by signing consent to participate in the study both by subjects and their families, while the exclusion criteria used in carrying out this study were as follows: (1) Schizophrenic patients with comorbid diabetes mellitus and (2) patients with a history of stroke, transient ischemic attack, epilepsy, and Parkinson's disease. We used the Indonesian version of MMSE that validated by Psychogeriatric Section on Psychogertaric of Indonesian Psychiatric Association; they divided the results of it into three categories: (1) Normal, (2) probable cognitive disorder, and (3) definite cognitive disorder, with the scores of 25-30 for normal, 18-24 for a probable cognitive disorder, and 0-17 for a definite cognitive disorder, respectively. The study was done after the authors were granted ethical clearance from the Health Ethical Commission of the Faculty of Medicine, Universitas Sumatera Utara. All of the subjects that met the inclusion and exclusion criteria would undergo the MMSE by MMA and EE to determine their cognitive level.

\section{Results}

\section{Characteristics of gender, age, educational background, and illness duration}

From Table 1, it can be observed that men were more prone to this disease $(62.5 \%)$, with an age range

Table 1: Characteristics of gender, age, educational background, and illness duration

\begin{tabular}{lll}
\hline Respondents characteristic & $\mathrm{n}$ & $\%$ \\
\hline Gender & 125 & \\
Men & 75 & 62.5 \\
Women & & 37.5 \\
Age & 18 & \\
15-24 years old & 92 & 9.0 \\
25-34 years old & 66 & 46.0 \\
35-44 years old & 24 & 12.0 \\
45-55 years old & & \\
Background & 20 & 10.0 \\
Primary school & 161 & 80.5 \\
Secondary school & 19 & 9.5 \\
University & & \\
IIIness duration (year) & 72 & 36.0 \\
$\quad$ >1 & 128 & 64.0 \\
\hline 1 & & \\
\hline
\end{tabular}

of 25-34 years $(46 \%)$, secondary school education background $(80.5 \%)$, and an illness duration $>1$ year $(64.0 \%)$.

\section{Cognitive function in schizophrenic}

\section{patients}

Table 2 showed that cognitive function in most schizophrenic patients was probable cognitive disorder (56.5\%).

Table 2: Cognitive function in schizophrenic patients

\begin{tabular}{lll}
\hline MMSE-scoring & $\mathrm{n}$ & $\%$ \\
\hline Normal & 61 & 30,5 \\
Probable cognitive disorder & 113 & 56,5 \\
Definite cognitive disorder & 26 & 13,0 \\
\hline
\end{tabular}

\section{Discussion}

A descriptive study with cross-sectional studies was used in carrying out this study. The results of the study using 200 subjects found that the most affected gender were male $(62.5 \%)$, between the ages of 25 and 34 years $(46 \%)$, with secondary school education background $(80.5 \%)$, and with an illness duration $>1$ year $(64.0 \%)$. Similar results were also found in the studies carried out by Kelly et al. [7], which found men to being the most affected. Talreja et al. [8] also found that every 100 schizophrenic subjects, $84 \%$ had cognitive dysfunction. In MMSE-scoring, when the total score is below 24, it should be considered as having probable cognitive dysfunction [9]. This study found that cognitive function in schizophrenic patients was probably cognitive impairment $(56.5 \%)$, with a score range of $17-23$. It is in line with the statement that schizophrenic patients have intellectual retentive abilities, even though certain cognitive deficits are likely to develop later [10]. Almost similar results were found in studies conducted by Fisekovic et al. [11], which found that MMSE scores in PwS were $24.9 \pm 3.3$ compared with our findings.

Age is considered to affect the cognitive dysfunction in schizophrenia, PwS was shown to have a deteriorated cognitive with increasing age compared to control [12]. In relation to sex, male PwS was found to experience serious cognitive deficits than female PwS [13]. The female PwS experienced better in immediate and delayed memory test [14]. These findings were supported by a study that was done, Zhang et al., as well [15]. According to a literature review made by Antonova et al. [16], the cognitive dysfunction in PwS was closely related to a decrease in gray matter density, temporal, and frontal lobe volume. Another research that supports this analysis was the study of Geisler et al. [17], which found that gray matter structure also had a relationship with cognitive dysfunction in people with schizophrenia. Some of the things that influence cognitive 
dysfunction in PwS include episodes of illness [18] and Estrogen [19]. Cognitive dysfunction in schizophrenia also prolongs the duration of the disease, worsens social functions, and increases the rate at which patients are being hospitalized [20], and the longer duration of the illness will show more cognitive dysfunction [8].

The limitations of this study include the lack of research comparison of cognitive dysfunction between men and women living with schizophrenia, which was done in the ward setting and the use of MMSE instrument. The MMSE instrument is not specifically designed for people with schizophrenia. Thus, in the future, we need a better instrument that is designed to screen cognitive dysfunction in schizophrenia, specifically.

\section{Conclusions}

Schizophrenia is a mental illness, one of which causes a decline in cognitive function in patients. Cognitive functions are needed to work on tasks given, such as communicating and interacting with others, and in carrying out daily activities. Until now, there has not been a study to know exactly what causes schizophrenia and cognitive decline. However, it has been thought that several parts of the brain play a role in this matter.

For patients living with schizophrenia and who experience cognitive dysfunction, it is advisable to get additional therapy other than the medicines they consumed, as this would improve their cognitive function. Some therapies that can be done are cognitive remediation therapy and cognitive behavioral therapy, though these therapies do not have satisfactory results. Further, understanding and study are needed to find the exact cause and the right therapy to improve it.

\section{Authors' Contributions}

All authors contributed equally to this work.

\section{References}

1. Sadock BJ, Sadock VA. Kaplan and Sadock's Synopsis of Psychiatry Behavioral Science/Clinical Psychiatry. $10^{\text {th }}$ ed. Philadelphia, PA: Lippincott Williams \& Wilkins; 2007.

2. Weickert TW, Goldberg TE, Gold JM, Bigelow LL, Egan MF, Weinberger DR. Cognitive impairments in patients with schizophrenia displaying preserved and compromised intellect. Arch Gen Psychiatry. 2000;57(9):907-13. https://doi. org/10.1001/archpsyc.57.9.907

PMid:10986554

3. Folstein MF, Folstein SE, McHugh PR. Mini-mental state exam In: Rush AJ Jr., Pincus HA, First MB, Blacker D, Endicott J, Keith SJ, et al, editors. Handbook of Psychiatric Measures. Washington, DC: American Psychiatric Association; 2000. p. 422-49. https://doi.org/10.1016/0022-3956(75)90026-6

4. Goldberg TE, Green MF. Neurocognitive functioning in patients with schizophrenia: An overview. In: Davis KL, Charney D, Coyle JT, Nemeroff CB, editors. Neuropsychopharmacology: The Fifth Generation of Progress. $5^{\text {th }}$ ed. Philadelphia, PA: Lippincott Williams \& Wilkins; 2002. p. 657-69. https://doi. org/10.1056/nejm200210173471624

5. Ong HL, Subramaniam M, Abdin E, Wang P, Vaingankar JA, Lee SP, et al. Performance of mini-mental state examination (MMSE) in long-stay patients with schizophrenia or schizoaffective disorders in a psychiatric institute. Psychiatry Res. 2016;241:256-62. https://doi.org/10.1016/j.psychres.2016.04.116 PMid:27203153

6. Portney LG, Watkins MP. Foundations of Clinical Research. $2^{\text {nd }}$ ed. Upper Saddle River, USA: Prentice Hall Inc.; 2000

7. Kelly C, Sharkey V, Morrison G, Allardyce J, McCreadie R. Nithsdale schizophrenia surveys 20: Cognitive function in a catchment-area-based population of patients with schizophrenia. Br J Psychiatry. 2000;177:348-53. https://doi. org/10.1192/bjp.177.4.348

PMid: 11116777

8. Talreja BT, Shah S, Kataria L. Cognitive function in schizophrenia and its association with socio-demographic factors. Ind Psychitary J. 2013;22(1):47-53. https://doi. org/10.4103/0972-6748.123619

PMid:24459374

9. Arapidis K, Rafou-Arapidi T, Taratsidou I, Fokas K, Kaprinis G. Assessment of cognitive function with MMSE in chronic schizophrenic inpatients. Ann Gen Psychiatry. 2006;5(1):S309. https://doi.org/10.1186/1744-859x-5-s1-s309

10. World Health Organization. International Classification of Disease and Related Health Problems. $10^{\text {th }}$ ed. Geneva: World Health Organization; 1993.

11. Fisekovic S, Memic A, Pasalic A. Correlation between MOCA and MMSE for the assessment of cognition in schizophrenia. Acta Inform Med. 2012;20(3):186-9. https://doi.org/10.5455/ aim.2012.20.186-189

PMid:23322976

12. Lee J, Green MF, Nuechterlein KH, Swerdlow NR, Greenwood TA, Hellemann GS, et al. The effects of age and sex on cognitive impairment in schizophrenia: Findings from the consortium on the genetics of schizophrenia (COGS) study. PLoS One. 2020;15(5):e0232855. https://doi.org/10.1371/ journal.pone. 0232855

PMid:32401791

13. Han M, Huang XF, Chen DC, Xiu MH, Hui L, Liu H, et al Gender differences in cognitive function of patients with chronic schizophrenia. Prog Neuropsychopharmacol Biol Psychiatry. 2012;39(2):358-63. https://doi.org/10.1016/j. pnpbp.2012.07.010 PMid:22820676

14. Li R, Ma X, Wang G, Yang J, Wang C. Why sex differences in schizophrenia? J TransI Neurosci (Beijing). 2016;1(1):37-42. PMid:29152382

15. Zhang B, Han M, Tan S, De Yang F, Tan Y, Jiang S, et al. Gender differences measured by the MATRICS consensus cognitive battery in chronic schizophrenia patients. Sci Rep. 2017;7(1):11821. https://doi.org/10.1038/s41598-017-12027-w PMid:28928440 
16. Antonova E, Sharma T, Morris R, Kumari V. The relationship between brain structure and neurocognition in schizophrenia: $A$ selective review. Schizophr Res. 2004;70(2-3):117-45. https:// doi.org/10.1016/j.schres.2003.12.002

PMid:15329292

17. Geisler D, Walton E, Naylor M, Roessner V, Lim KO, Schulz CS, et al. Brain structure and function correlates of cognitive subtypes in schizophrenia. Psychiatry Res. 2015;234(1):74-83. https://doi.org/10.1016/j.pscychresns.2015.08.008

PMid:26341950

18. Kalwa A, Rzewuska M, Borkowska A. Cognitive dysfunction progression in schizophrenia-relation to functional and clinical outcome. Arch Psychiatry Psychother. 2012;14(1):5-13.

19. Ko $\mathrm{YH}$, Joe SH, Cho W, Park JH, Lee JJ, Jung IK, et al. Estrogen, cognitive function and negative symptoms in female schizophrenia. Neuropsychobiology. 2006;53(4):169-75. https:// doi.org/10.1159/000093780

PMid:16763376

20. Wciórka J, Bembenek A, Hintze B, Kühn-Dymecka A. Schizophrenic disorders-do cognitive dysfunctions relate to course characteristics and the psychopathological picture? Arch Psychiatry Psychother. 2007;4:5-17. 